\title{
Innovative Practice of Hainan Miao Costume Pattern in Graduation Design Teaching
}

\author{
Zhang Lili \\ Haikou University of Economics, Haikou, Hainan 571127
}

Keywords: Hainan Miao Costumes, Humane Value, Graduation Design Teaching

\begin{abstract}
Miao is one of the ancient peoples of China, whose costumes and patterns not only have national characteristics, but also have important humane values such as society, history, art and folklore. However, the Hmong Miao costumes in Hainan are combined with local culture and history with unique patterns significance. The integration of Hainan Miao costume design with graduation design teaching can not only deepen the connotation of graduation design and enrich the creative forms, but also promote the development and innovation of national culture.
\end{abstract}

\section{Introduction}

As one of the ancient peoples of Hainan Island, Hainan Miao people have the symbolic meaning and spiritual connotation of the geographical and ethnic culture in the costumes. Through the research on the Hmong costumes in Hainan, the students can understand the values of history, culture and folklore contained in the Hmong costumes of Hainan more deeply and combine them with the graduation design teaching of the visual communication design specialty [1]. Using the unique artistic language, the excavation of its human story, aesthetic taste, totem meaning and national spirit has important theoretical significance for the protection and inheritance of Hainan Miao folk art culture. To a certain extent, it is the transformation of college graduation teaching and student innovation Ability to provide a reference model of teaching.

\section{The Artistic Characteristics and Cultural Connotation of Hmong Miao Costumes}

\subsection{Hainan Miao costumes visual aesthetic features}

Hainanese Miao costumes are drawn from a wide range of subjects. As far as their themes and content are concerned, they mainly include two aspects: the memory of the national humanities history and the freehand writing of the natural objects [1]. While maintaining the natural spirituality, the Miao nationality inherits the history and culture, Apparel in the design, nature reverence and love manifested. Through the individual, composite and combination of patterns, showing a beautiful vision of life, admiration for history and respect for life and nature; through cotton weaving, batik, embroidery patterns, demonstrated the superb skills, rich experience and unique aesthetic concepts through the vivid contrast of color and strong performance of the nation's aesthetic spirit and longing.

\subsection{Hainan Miao costumes cultural connotation}

The history and culture of Hainan Miao have a long history. With the changes of life and social environment, they are also continuously creating patterns. The pattern of clothes in costumes is the carrier of national culture and history. The living environment, culture and history vivid records; totem in the pattern, in addition to expressing love and happiness and record life, but also contain folklore and symbolism, such as butterfly pine pattern, meaning love between lovers like pine evergreen. Bird patterns, meaning Miao people describe their sense of belonging, reflecting the longing for a better life [2]. Daqingshan pattern, a symbol of hard-working and wise Miao people, vividly demonstrated the spirit of Hainan's Miao traditional culture and the arts, is a living fossil of history, culture, folklore and awareness. 


\section{Hainan Miao Costumes Pattern Classification}

\subsection{Geometric pattern}

The earliest human creation and use of the pattern are geometric patterns, the basic synchronization with the use of textile technology. In Miao costumes, geometric patterns appear the most frequently, the scope of application is the most extensive. The main geometric patterns include circular pattern, zigzag pattern, water wave, cross pattern, grid pattern, well pattern, crease pattern. In the decorative arrangement, the main is the Quartet continuous, symmetrical combination, the auxiliary is two continuous lines, fold lines and water ripples [2].

Only when dressed in attendance, Hainan Miao people will wear their own national traditions, geometric patterns are generally embroidered in the clothes cuffs, necklines, skirts, belts and short skirts hem position. Although the cities and counties inhabited by Hainan Miao people are different from the villages, the difference between geometric patterns and geometric patterns is not obvious.

\subsection{Animal pattern}

In Hainan Miao costumes, extensive use of animal patterns, animal patterns more exaggerated shape, the shape is very image. Among the animal patterns, cattle, dragons, fish, flying birds, double-headed birds, butterflies, pans, are the more common patterns [3]. In addition, there are many imaginary animals that embody the rich imagination and creativity of Hainan's Miao people.

\subsection{Plant pattern}

Hainan Miao costumes patterns, plant patterns appear more patterns. Hainan Miao good use of plant parts, such as plants or flowers leaves, stems, flowers and rattan often as the main part of the performance of interception. Usually used in apparel at the collar, skirt, belt, cuffs and headscarves and other locations, mainly in the form of auxiliary pattern, exist in the main graphics around [3]. The gourd, bamboo, banyan, maple, fern leaf plants as the main plant patterns repeatedly appear.

\subsection{Other patterns}

In addition to the above patterns, such as human-shaped patterns, text patterns, will also appear in Hainan Miao costumes, mostly supporting the role of embellishment, and after extraction, simplification, deformation and exaggeration practices, highly decorative, such as yin and yang gossip pattern. The text and graphics are affected by local culture, especially the influence of Chinese culture, often can see the Chinese pattern [4]. Visible, Hainan Miao costumes both inherit and develop the language of this nation, but also by the influence of local culture and customs, in the long river of history continue to develop and innovate.

\section{Hainan Miao Costumes in the Graduation Design Teaching Innovation and Practice}

\subsection{Deconstruction of the pattern element}

Hainan Miao costumes, the pattern is not only a text substitute, but also a spiritual expression, is a manifestation of national spirit, Hainan Miao people in the long-term living work will be the traditional nationalities, legends and other forms in the form of integration into clothing, through the natural prototype, direct expression of natural things and abstract natural objects to express, directly to express their true thoughts and emotions. With the development and progress of the times, the society is constantly moving in a diversified direction. In the traditional patterns of the Miao people, new themes and contents have also begun to be tried and the designs become more complicated, delicate, delicate and intuitive. In the graduation design teaching, we should pay attention to the pattern of a comprehensive analysis and study, can be combined with the totem clothing patterns connotation and implication of cultural connotation to give a profound analysis and cognition, clothing patterns as the emotional transmission of media, from the pattern Learn from creative sources and ideas [3]. 


\subsection{Graphic elements of the extension and re-design}

Whether it is Miao dress patterns, colors, shapes, or its art practices, forms of expression, cultural characteristics, all for graduation design teaching provide many design elements. Through the mastery and in-depth exploration of its manifestations and art practices, the Miao clothing design elements are pointedly used from the appropriate starting point to guide students to carry out purposeful restructuring, decomposition and engineering to showcase new works of art, the modern design of the national atmosphere to the world stage [4].

In this year's graduation project, we tried to integrate the traditional patterns of Miao costumes into the creative ideas of students and different creative media. For example, in various forms such as illustrations, picture books, package design, style jewelry packaging design and production, "color" graphic design and production of graduate design projects such as teaching guidance will be included, including ethnic minority costumes in Hainan Miao and modern packaging design, brand design and picture books and other forms of expression to achieve the traditional Art culture is a new performance. In the costume design and production project of color clothes, taking the fashion culture of Hainan Li, Miao and Hui together with the modern station costumes, the minority costumes of Hainan is vividly expressed in the form of picture books [3]. Graduation design creation form, deepens the content, reflecting the characteristics of the discipline suited to local conditions.

\subsection{Deconstruction of color elements}

Hainan Miao is a colorful and comfortable people. This is also reflected in the colors of the costumes, with elegant colors, colorful colors, attention to the use of contrasting colors and transition colors, expressing certain regional cultures and national spirits, be different, very local characteristics. Hainan Miao costumes mostly take the color of black, blue indigo and other dark as the background, through the use of high purity and hue with the color, strong decorative, while focusing on the color area, cold and warm, etc., with a strong sense of rhythm and rhythm sense. Such as Miao costumes in the more common blue and red color contrast, through the staggered heating, making costumes bright, and good at using silver with, and complement the color of clothing [4]. At the same time, different colors of clothing also reflect the color changes, young women use bright colors, such as the turban patterns and more colorful, older women tend to be plain, most of the turban color is a uniform indigo color. Visible Miao people in the long-term practice of life to explore, summed up with the national characteristics of the aesthetic characteristics and color style. In teaching, attention should be paid to guiding students to pay attention to the analysis of the law of the traditional color of Miao costumes, combining with the current knowledge of color science, exploring the contrast and research from many aspects, and exploring the wisdom of the Hainan Miao people.

\subsection{Color elements of the extension and application}

Compared with the graphics, color can be more emotional transmission and expression. Miao costumes with its own history of color patterns, which are in different periods, showing different color emotions and symbolic meanings. In the process of graduation design teaching, teachers need to pay close attention to the application and extension of the elemental color, and pay attention to guiding students to analyze the law of their color and the long-term life of the times, national spirit, customs and other in-depth analysis to understand the color implied symbolic value and cultural value is more important. In this way, the combination of color and spirit can make the work more vivid and soulful [1]. In specific applications, it is not a simple application of new ideas to reconcile the differences between colors and modern design. It is necessary to have deep understanding of the color of Miao clothing patterns, contact with the structure, self-awareness and expression, different media, performance themes to be transformed and re-designed to reflect the characteristics of ethnic works. 


\section{5 "Italian" application}

The meaning of "meaning" means that under the precondition of knowing and grasping the traditional cultural meanings of the pattern part, it carries on the recreational activities to the pattern, and then inherits the implication of the traditional pattern. In the living environment of Hainan's Miao people, it is less influenced by the advanced culture of the external nation and aesthetic feelings of the predecessors. Through the Miao costumes, the philosophical thoughts of history, culture and customs as well as religious beliefs can be recorded, such as the patterns of animals and plants in costumes, the cultural customs of Hainan Miao, and the indirect primitive performance of the primitive and simple philosophy of Hainan Miao. [2] The pictures of natural scenery show the cultural implication of Hainan's Miao people worshiping nature. In the graduation design teaching, analyzing and rebuilding the Miao nationality costume pattern design is the application of its culture advocating idea, which needs to be fully infiltrated and integrated in the graduation design teaching process so that the "artistic conception" of the pattern is more aesthetic, "Meaning" more far-reaching. It is also required that students be creatively integrated with the ideas of the students, to excavate the meaning of the patterns of Miao clothing on the traditional basis.

\section{Conclusions}

As a material carrier of national culture, Hainan Miao costumes show the life, folklore and religious beliefs of Miao people. Each pattern reflects the national spirit of Hmong people in Hainan, which shows the development and variability of Hainan Miao culture, Particular and inclusive. The combination of Miao costume design and graduation design teaching is one of the feasible ways to realize the reinvention of national art culture and the localization of contemporary design, and to integrate the cultivation of innovative ability with modern design teaching and local culture research. It is hoped that this will provide a place, method and train of thought for the preservation, continuation and development of national art culture and create a new ecological environment for its sustainable development.

\section{Acknowledgements}

This paper was based on education science project of Hainan Province's " 13th Five-Year Plan ","Hainan Miao Folk Art as the Core of the Graduation Design Innovation Teaching Research" (subject code: QJY13516056), and project of Haikou University of Economics, "Educational Orientation of Hainan Ethnic Folk Art Cultural Value"(project code: HJKY17-08).

\section{References}

[1] Cao Fangyuan. Hainan Miao costumes and artistic characteristics of packaging design in the application of research [D]. Master's thesis (on), 2016, 05-08.

[2] Di Dilong. Traditional and modern integration - Guizhou Miao traditional costumes in the current art of furnishings [J] Beauty and the Times (on), 2017 (03): 82-84.

[3] Chun Yubu, Yang Wen-bin. Guizhou Miao Costumes and Traditional Chinese Culture [J]. The Journal of Ecology National Culture, 2015, 7 (02): 107-116.

[4] Bai Ruirong. Application of Guizhou Miao Costumes in Package Design of Tourism Crafts [J]. Packaging Engineering, 2013, 34 (22): 24-26. 